\title{
De l'étiologie du farcin de zébus tchadiens : nocardiose ou mycobactériose?
}

\section{I. - Étude bactériologique et biochimique}

\author{
par G. CHAMOISEAU
}

I. E. M. V. T. Laboratoire de Recherches Vétérinaires de Farcha, Fort-Lamy (Tchad)

\begin{abstract}
RÉsumé
Un germe de la classe des Actinomycétales considéré comme appartenant au genre Nocardia, est isolé d'abcès ganglionnarres chez des zébus tchadiens; son étude bactérıologique montre qu'ıl est différent de $\mathrm{N}$. forcinica et incıte, pour parfaire sa défermınation, à procéder à l'analyse de sa constıtutıon chimique.
\end{abstract}

\section{INTRODUCTION}

Le farcin du zébu du Tchad a inspiré de nombreux travaux. Ceux-ci ont consacré le rôle d'une Actinomycétale dans l'étıologie de l'affection. Mais en fassant admettre ce germe pour N. farconica, ils n'ont pu établir de rapports précis entre cette espèce tchadienne et l'espèce type du genre. Cette incertıtude appelait un supplément d'informations, d'autant plus que, si la maladie elle-même est bien connue, peu d'études ont été menées pour approfondır les caractéristiques de l'agent causal. Celles qui ont été faites à Farcha, ont permıs de compléter les connaissances acquises sur l'actinomycétale des zébus du Tchad, de préciser les particularites qui la différencient de $N$. farcinica et surtout d'établir sa véritable nature de Mycobactérıe révélée par sa composition lipidique.

Le présent travail a pour objet l'étude bactériologique de cette espèce microbienne ; un suivant traitera de ses constituants lipidiques.

\section{I. - MATÉRIEL ET MÉTHODE}

\section{A) Le germe.}

Il a été régulièrement isolé du pus d'abcès ganglionnaires de zébus sacrifiés aux abattoirs de Fort-Lamy et d'Abéché. Toutes les souches qui ont été rencontrées se sont régulièrement manıfestées sous la même apparence microscopique; avec le même comportement cultural et le même pouvoir pathogène expérimental pour le cobaye. Une seule d'entre elles, pour des raisons d'ordre matériel, a pu être étudiée du point de vue biochimique.

\section{B) Méthode.}

La méthode de travall s'est inspirée de technıques mises en œuvre classıquement dans l'étude des Actinomycétales (4, 5, 7, 9, 10, 11, 12, 14).

10 L'étude bactériologique a envisagé l'isolement, les caractères microscopiques dans les produits pathologiques et en culture. Les milieux suivants ont été utilisés :

- Milieux solides : milieu de COLETSOS base de l'Instıtut Pasteur: milieu de LCEWENSTEINJENSEN; milieu de SABOURAUD: gélose ordınaıre: gélose tryptone sımple ou enrichı de sérum de cheval ; gélose EUGONAGAR simple ou additionnée du même sérum.

- Milieux liquides : la culture en milieux lıquides a eu pour but d'obtenır une grande masse de germes et d'antigènes. De ces milieux ne seront cités que ceux qui autorisaient des 
espoirs ou donnèrent satisfaction : milieux de SAUTON simple ou enrichi de sérum ; milieu de YOUMANS; bouillon trytone sérum identique au milieu solıde ci-dessus, la gélose en moins.

$2^{\circ}$ L'étude biochimique a porté sur les substances hydrocarbonées, les acides organiques ef les substances azotées. Des tests biochimiques envisagèrent la mise en évidence d'une catalase, d'une nitrate réductase, la transformation du citrate de fer ammoniacal, la fixation du rouge neutre. Enfin ont été appréciées les déviations imprimées au métabolısme par l'I. N. H., l'acide para-aminosalıcyclique (P.A.S), l'éthionamıde, la viomycine, la cyclosérıne, la streptomycine, la kanamycine.

Les différents substrats furent incorporés à des milieux synthétiques ou complexes, gélosés ou non, dont la composition rappelle celle des milieux qu'utilise MARIAT (4, 10, 11).

De la sorte, onze hydrates de carbone et cing acides organiques ont été proposés comme source de carbone.

L'attaque des substances azotées a été appréciée en ce qui concerne la gélatine, la casélne, la tyrosine, la xanthıne, I'hypoxanthine, l'urée.

L'action des antibiotiques fut survie sur le milieu de Jensen de I'Instıtut Pasteur imprégné, en présence de tournesol, des antibiotiques cités plus haut.

3o Ensemencement des milieux : l'émulsion du germe étant très difficıle, des colonies en ont été écrasées sur la surface des milieux gélosés ef leurs débris répandus. Les mılıeux liquides reçurent également des fragments de colonies. Les inoculums étaient fournis par une culture de 4 semaines sur la gélose tryptone sérum.

40 Incubation. Les cultures ont été gardées à l'étuve pendant six mols et furent examinées le plus souvent possible. Les antibiogrammes ont été enregistrés à partir du moment où les tubes témoins présentèrent une culture de développement normal, c'est-à-dıre après quinze jours. Ils furent néanmoins suivis pendant deux mois.

$5^{\circ}$ Lecture des résultats: Ils sont appréciés en fonction de la densité des cultures sur les milieux d'étude, du virage de l'indicateur coloré, des modifications des milieux dues aux cultures. Ces modifications étant mises en évidence, à l'occasion, par des réactıfs appropriés.
60 Tests biochimiques.

- Recherches de la catalase : selon la technique décrite pour les Mycobactéries.

- Recherche de la nitrate réductase : d'après ia méthode de VIRTANEN modifiée par BOISVERT.

- Production d'acide nicotınique : mise en œuvre du niacin-test des Mycobactéries.

- Transformation du citrate de fer ammoniacal : Test exécuté comme dans l'étude classique des Mycobactéries.

- Epreuve de la fixation du rouge neutre : selon le procédé de MIDDLEBROOK-DUBOS.

\section{II. - RÉSULTATS}

\section{A) Etude bactériologique.}

10 Isolement. II a été jusqu'à présent très simple. Lorsque les colorations de GRAM et de ZIEHL ne révèlent dans le pus du ganglıon aucun autre germe, il est étalé directement à la surface du milieu de COLETSOS, sans autre traitement préalable queson émulsion dans la quantité d'eau distillée stérile suffisante pour 6 tubes. Lorsque le pus est souillé, ce qui est rare, on peut le traiter par la pénicıllıne ou la streptomycine, et non par le bromure de cétyl pyridinium, ou l'inoculer à un cobaye chez qui Il provoquera un abcès où l'Actinomycétale sera en culture pure.

Dans les produits pathologiques et les lésions le frold conserve bien le germe.

Des cultures sont aisément repiquables après un an de conservation à $+4^{\circ} \mathrm{C}$. Par contre après deux ans de stockage à la même température ces cultures comportent un grand nombre d'éléments microbiens morts, et les survivants repiqués mettent près de deux mois avant de donner des colonies, qui par la suite, évoluent normalement.

\section{$2^{\circ}$ Morphologie.}

a) Dans les produits pathologiques.

Le germe s'y présente selon l'image classique d'un lacis de filaments enchevêtrés portant des ramifications. Il est difficile de saisir sur un frottis de pus coloré au Ziehl ou au Gram la totalité de ces éléments car ils ne se désalidarisent pas 
d'une gangue de cellules nécrosées. Sı bien que souvent, sur une préparation colorée au Ziehl B. H. selon FITE, ou au Ziehl classique, on voit de très nombreux mycéliums colorés en rouge vif, émergeant d'un fond bleu de cellules nécrosées, ce qui réalise l'image d'un «buisson ardent).

On peut libérer les touffes mycéliennes de leur gangue de cellules mortes en imprimant au pus une vive agitation mécanique dans l'eau distillée. Il est possible alors de réalıser des frottis sur lesquels la coloration révèle le lacis de germes complétement disséqué, sans qu'on puisse pour autant en suivre de bout en bout toutes les circonvolutions.

Les filaments de $0,5 \mu$ environ de diamètre, Gram positifs et acido-aicoolo-résistants, se présentent homogènes avec parfois des granulations foncées séparées par des espaces plus clairs. Ces granulations se situant solt sur le filament principal soit au point d'articulation de ce dernier avec une ramification.

Dans le pus d'abcès expérimentaux de cobayes tendant à la guérison, ou dans celui en vole de calcificatıon de ganglıons de bovins, l'Actınomycétale peut se présenter en amas de formations bacillaires renflées en leur centre, acıdo-alcoolorésistants, solidaires d'une gangue nécrosée rappelant soit des Mycobactéries, soit des Corynebactéries qui garderaient le Ziehl. Ces formatıons bacillaires ont toujours donné des colonies typiques, et dans les lésions expérimentales du cobaye elles sont toujours ressorties sous leur forme évolutive filamenteuse.

b) En culture.

Sur les milieux solides les colonies ont presque toujours le même aspect.

- Milieu de COLETSOS base : C'est le milieu qui nous a servi régulièrement pour l'isolement du germe. Après 15 jours à 3 semaınes d'ıncubation à $37^{\circ} \mathrm{C}$ on constate l'apparition de colonies sphériques, brillantes, régulières, transparentes d'abord, gouttes de miel tranchant sur le fond mat du milieu. A ce stade ces colonies ont un demi-millimètre environ de diamètre. Ces sphères grossissent lentement pour donner des formatıons mûriformes. Cette évolution se dessine par une ambilication centrale d'où partiront quatre à six dépressions linéaıres rayon- nantes qui délimiteront d'autres éléments sphérıques. Ces derniers constıtuent l'unıté architecturale de base des formes coloniales plus évoluées. En grossissant, ces amas de sphères, qui vont se fusionnant progressivement, se disposent selon des ensembles de forme inattendue. dont seule la photographie peut rendre un compte exact (photos 1 et 2).

Ces colonies grossissent avec le temps en fonction de l'espace dont elles disposent sur le milieu et s'y accrochent d'autant plus qu'elles sont plus grosses.

Elles sont parfois pigmentées en jaune miel. Mais l'intensité de cette pigmentation dépend de l'âge de la culture. Très rarement certaines vieilles colonies, ou des colonies trop nombreuses sur un mılieu qui s'épuise sont surmontées d'un léger duvet qui leur donne un aspect givré.

- Milieu de LEWENSTEIN-JENSEN. Les colonies ont ici le même aspect.

II est très Important de noter que sur les milieux de LEWENSTEIN et sur celui de COLETSOS qui sont mats, les colonies qui ontatteint une certaine taille ou les cultures en nappe sont bordées d'une auréole moirée à plusıeurs étages rappelant un arc-en-ciel. II semble que les germes secréteraient une substance lıpidique qui, s'étalant par vagues sur le milieu, provoquerait cette auréole bien visıble lorsqu'on l'observe sous un certain angle.

- Gélose tryptone sérum. La culture démarre 8 à 10 jours après repıquage et elle est du même type que sur Coletsos. Comme sur ce dernier milıeu révolution est très longue, et il faut bien attendre un mois pour être sûr que tous les débris de l'ınoculum ont poussé.

- Gélose tryptone sans sérum et gélose ordinaire permettent la crolssance, mais les colonies sont beaucoup moins belles et nombreuses. Elles sont moins brillantes, moins pigmentées ef semblent pour certaines livides.

- Gélose EUGONAGAR. Même enrichi de sérum, ce milieu reste moins bon que la gélose tryptone sérum. Les colonies icı ressemblent à celles obtenues sur Coletsos mais elles sont moins nombreuses.

- Gélose de SABOURAUD. Ne peut assurer la culture. 


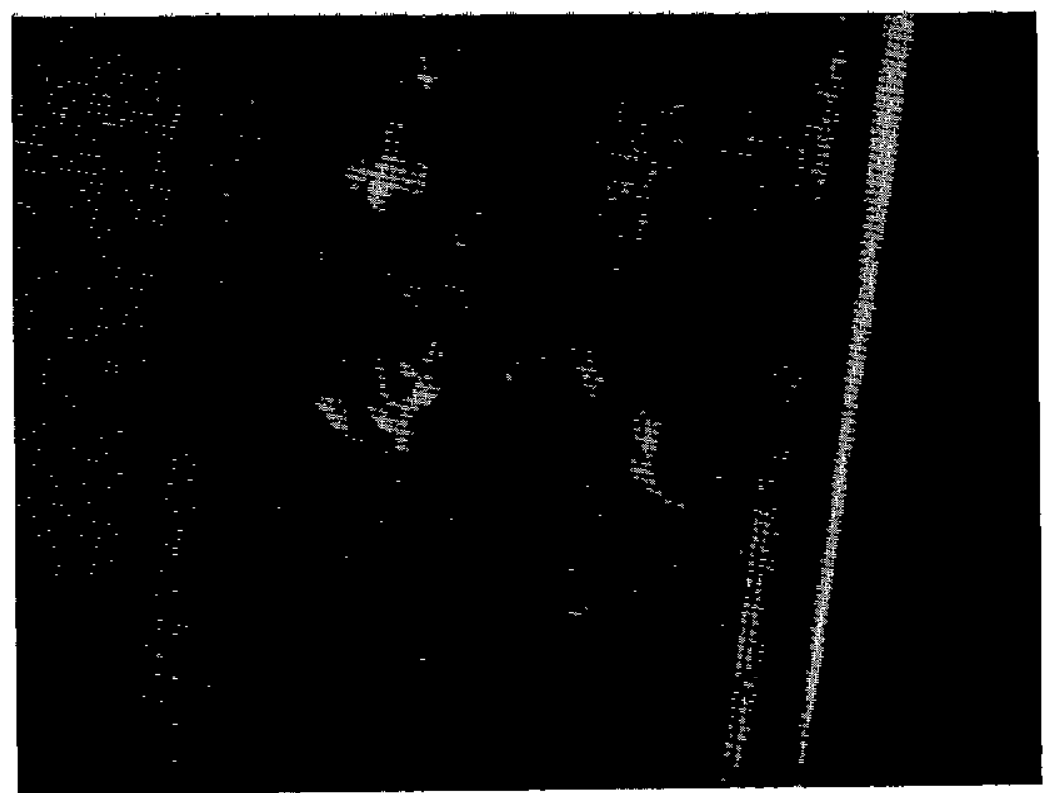

Photo 1. - Colonies repiquées sur Coletsos Les plus grosses Formations résultent de la croissance plus rapide des plus gros débris de l'inoculum (1 mois d'incubation).

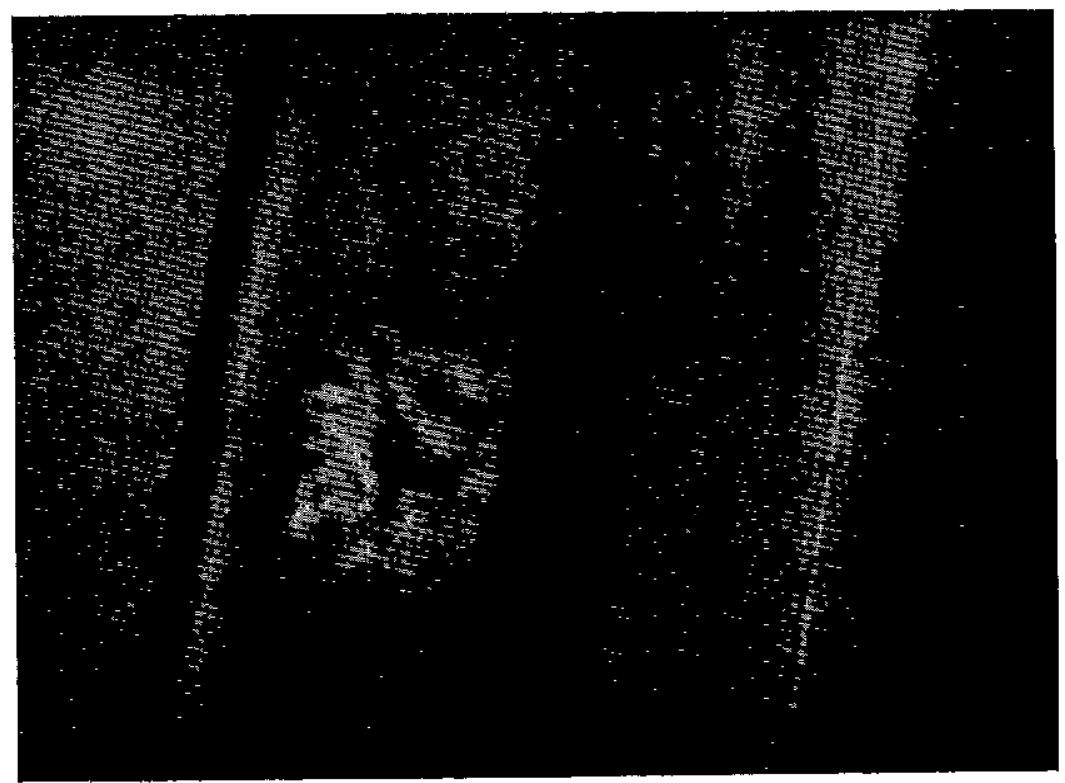

Photo 2. - Colonie sur milieu de COLETSOS (2 mois d'incubation). 


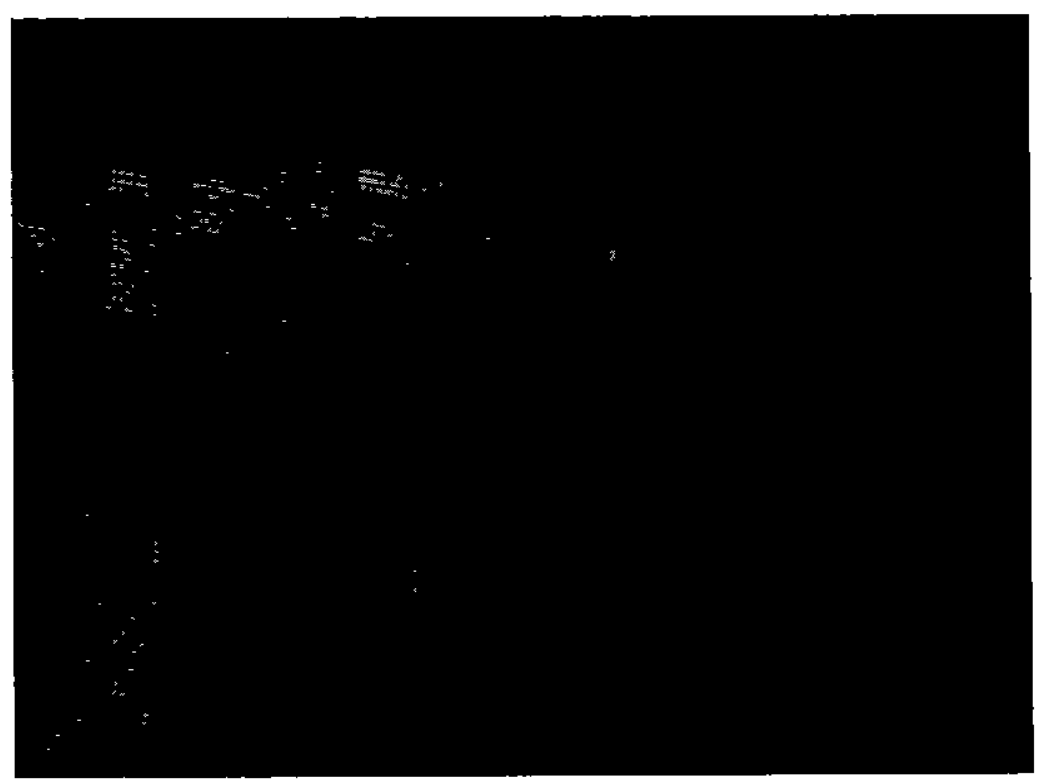

Photo 3. - Culture en bouillon tryptone sérum après un mols d'incubation. Le voile remonte le long de la paroı du tube. Le bovilion reste claır.

D'où qu'elles viennent ces colonies ne se laissent pas émulsionner même en présence de tween BO. Pour faire des repiquages, ou faire des inoculations il faut les écraser. La substance grasse qui enrobe les éléments microbiens fait, alors que les débris collent à la paroi des tubes ou flattent à la surface du liquide sı leur masse est faible. Dans ces conditions ıl est très malaısé d'apprécier l'opacité d'une suspension.

Le germe s'adapte mal aux milieux liquides:

- Milieu de SAUTON : simple ou enrichi de sérum il n'est pas favorable à une culture abondante.

Après un mois d'incubation, on obtient avec le Sauton au sérum :

- en surface : voile très fin, diaphane, n'arrıvant pas à atteindre les parois du ballon ;

- sur les paras : en dessous de la surface libre du mılıeu, même valle plaquant irrégulièrement le verre et glissant progressivement vers le fond tout en se plissant:

- au fond du ballon : fin sédiment blanchâtre que constıtue l'accumulation de morceaux de voile ;

- le milieu reste clair ; la culture n'évolve pas après deux mois et s'arrête après n'avoir donné qu'une masse insignifiante de germes.
- Milieu de YOUMANS : culture insignıfiante ou nulle.

- Bovillon tryptone sérum : culture belle quolqu'irrégulière parfois.

Après 3 semaınes à 1 mois d'incubation, la même souche peut évoluer de deux façons. On peut observer en effet d'un côté une culture sous une forme «smooth», d'un autre côté une culture « rough » (photo 3 ).

- Culture «smooth»: pellicule superficielle très fine, discrète, faıte de graıns blanchâtres prolongés dans la masse du liquide par un filament muqueux. Le lıquide claır au début s'obscurcit avec l'accrolssement du nombre de ces filaments. A la longue un dépôt abondant et muqueux occupe le fond du ballon. Ce dépôt est de coloration saumon clair. II révèle la présence d'éléments ramifiés très rares, acidoalcoolo résıstants, que remplacent massivement des éléments coccoides perdant progressivement leur acido-alcoolo résıstance pour, à un stade ultime ne garder que le Gram et faiblement. Il est intéressant de noter que les formes ramifiées présentes dans le sédiment perdent leur belle régularité pour présenter des renflements simulant des ventres ou des spores terminales.

- Culture «rough »: Elle offre l'aspect suivant après 1 mois d'incubation : 
- en surface : voile épais et granuleux de 1 à $1,5 \mathrm{~mm}$ d'épaisseur, d'aspect rugueux et plissé, d'apparence sèche et de couleur blanche. Ce voile est fait de grains sphérıques juxtaposés constituant un réseau consistant, flottant nettement et tendant lorsqu'il atteint les paross du verre à y grimper pour poursulvre son développement aux dépens du film de milieu.

- Le boullion reste parfaitement clair.

- Avec le temps des fragments de voile peuvent tomber au fond du ballon et y constituer un sédıment granuleux dont la couleur s'obscurcit lentement. Un fragment du volle de surface est repiquable sur un milieu neuf.

L'examen microscopique révèle la structure filamenteuse et ramifiée originelle du germe ainsi que son acido-alcoolo résistance et son immobilité.

\section{B) Activité biochimique.}

Les résultats de l'étude de cette activité biochimique sont résumés dans les tableaux : I, II, III, IV, V.

Tableau I: Utilisation des hydrates de carbone en milieux solıdes et en milieux lıquides.

Tableau II : Utilisation des acides organiques en milieux solides et en milieux liquides.

Tableau III : Utilisatıon des substances azotées. Les substrats sont incorporés dans des milieux rappelant ceux de MARIA T (1963).

\section{TABLEAU $N^{\circ} \mathrm{I}$}

Utilisation des hydrates de carbone en milieux solides et en milieux 11quides

\begin{tabular}{|l|c|c|}
\hline & $\begin{array}{c}\text { Milieux } \\
\text { Gélosés }\end{array}$ & $\begin{array}{c}\text { Milieux } \\
\text { Liquides }\end{array}$ \\
\cline { 2 - 3 } Lactose & - & - \\
Saccharose & - & - \\
Arabinose & - & - \\
Xylose & - & - \\
Galactose & - & - \\
Glucose & - & ++ \\
Levulose & +++ & +++ \\
Mannose & +++ & - \\
Inositol & - & - \\
Mannitol & - & - \\
\hline
\end{tabular}

TABLEAU $N^{\circ} I I$

Utilisation des acides organiques en milieux solides et en milieux liquides

\begin{tabular}{|l|c|c|}
\hline & $\begin{array}{l}\text { Milleux } \\
\text { Gélosếs }\end{array}$ & $\begin{array}{l}\text { Milieux } \\
\text { Liquides }\end{array}$ \\
\cline { 2 - 3 } Pyruvate & ++ & - \\
Citrate & ++ & ++ \\
Benzoate & ++ & ++ \\
Acétrate & \pm & - \\
Malonate & - & - \\
\hline
\end{tabular}

TABLEAU $\mathbb{N}^{\circ}$ III

Utilisation des substances azotées ${ }^{+}$

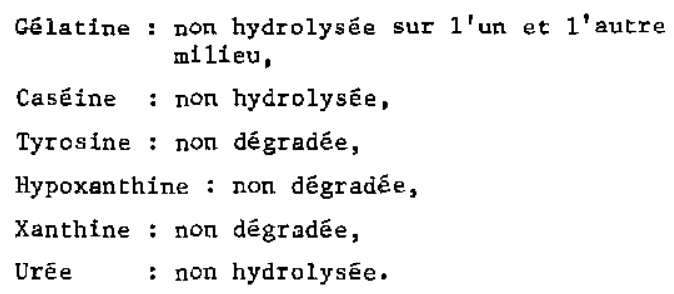

$+=$ Les substrats sont incorporês dans des m11ieux rappelant ceux de Mariat (1963).

Tableau IV : Sensibilité aux antibiotiques in vitro.

Tableau $V$ : Réponses aux tests biochimiques.

\section{C) Discussion.}

Les études que l'on peut entreprendre sur cette espèce microbienne sont rendues malaisées du fait de ses exigences nutritives, de sa croissance lente, de sa difficile adaptation aux milieux liquides, de son refus de s'émulsionner.

Cela seul justifierait l'étude de son activité biochimique dont on peut dire qu'elle se ramène pour becucoup à un problème de culture.

En effet aucun des milieux d'étude utılısés ne s'est montré favorable à une culture abondante. Aucun d'eux n'a pu fournir la somme de métabolites essentiels et d'énergie que requiert une croissance optımale. Mais quoıque les cultures y soient restées maigres les colonies ont présenté l'aspect qu'elles offrent sur des milieux plus favorables.

La souche étudiée s'est montrée indifférente à tous les substrats azotés qui lui ont été pro- 
TABLEAU $N^{*} \mathbf{I V}$

Sensibilite aux antlblotiques in vitro

\begin{tabular}{|c|c|c|c|c|c|c|}
\hline \multirow{2}{*}{ Antibiotiques } & \multicolumn{4}{|c|}{$\begin{array}{l}\text { Culture du germe en fonction des } \\
\text { concentrations } \mathrm{d}^{\dagger} \text { antibiotiques au } \mathrm{cm}^{2}\end{array}$} & \multirow{2}{*}{$\begin{array}{l}\begin{array}{l}\text { Culture } \\
\text { témoin }\end{array} \\
++++\end{array}$} & \multirow[t]{2}{*}{ Conc $14510 n$} \\
\hline & $\begin{array}{l}0,1 \text { r } \\
++++\end{array}$ & $\begin{array}{l}0,2 \gamma \\
++++\end{array}$ & $\begin{array}{l}0,5 \% \\
+++++\end{array}$ & $\begin{array}{r}1 Y \\
++++\end{array}$ & & \\
\hline P.A.S. & $\begin{array}{l}0,1 \gamma \\
++++\end{array}$ & $\begin{array}{l}0,5 Y \\
++++\end{array}$ & $\operatorname{lin}_{++++}^{\gamma}$ & $\begin{array}{r}5 \gamma \\
++++\end{array}$ & ++++ & Résistant \\
\hline Echlonamide & $\begin{array}{l}2 y \\
++++\end{array}$ & $\begin{array}{l}4 y \\
++++\end{array}$ & $\begin{array}{ll}8 \\
8 \\
++++\end{array}$ & $\underset{++++}{16}$ & +++4 & Rêsistant \\
\hline Viomycine & $\begin{array}{l}10 \gamma \\
-\end{array}$ & $\begin{array}{l}20 Y \\
-\end{array}$ & $\begin{array}{c}30 \\
-\end{array}$ & $\begin{array}{l}40 Y \\
-\end{array}$ & +++ & Sensible \\
\hline Cyclosërıne & $\begin{array}{l}10 Y \\
+\end{array}$ & $\begin{array}{c}20 \gamma \\
+\end{array}$ & $\frac{30}{+} \gamma$ & $\begin{array}{c}40 \gamma \\
+\end{array}$ & ++++ & Senstble : bactērlostase à $30 \gamma$ \\
\hline Streptomycine & $\begin{array}{l}1 Y \\
++++\end{array}$ & $\begin{array}{l}5 y \\
++++\end{array}$ & $\begin{array}{l}10 \gamma \\
++++\end{array}$ & $\begin{array}{l}50 \text { y } \\
++++\end{array}$ & +++ & Rêsistant \\
\hline Kanamyc1ne & $\begin{array}{l}4 \gamma \\
+\end{array}$ & $\begin{array}{l}8 Y \\
-\end{array}$ & $\begin{array}{c}16 \gamma \\
-\end{array}$ & $\begin{array}{c}32 \gamma \\
-\end{array}$ & ++++ & Sensible; bactériostase à $4 \gamma$ \\
\hline
\end{tabular}

TABLEAU $\mathrm{N}^{\circ} \mathrm{V}$

Réponses aux tests biochimiques

\begin{tabular}{|c|c|c|}
\hline Catalase & +++ & $\begin{array}{l}\text { dëgagement très rapide et très } \\
\text { abondant de bulles. }\end{array}$ \\
\hline Nitrate réductase & ++ & mélange rouge clair \\
\hline $\begin{array}{l}\text { Production d'acide } \\
\text { nicotinique }\end{array}$ & - & mëlange incolore \\
\hline $\begin{array}{l}\text { Transformation du citrate } \\
\text { de fex ammoniacal }\end{array}$ & - & $\begin{array}{l}\text { la couleur des colonies reste } \\
\text { lnchangée. }\end{array}$ \\
\hline Fixation du rouge neutre & & $\begin{array}{l}\text { le culot de centrifugation est } \\
\text { franchement jaune comme celui que } \\
\text { donne une Mycobactérie avirulente. }\end{array}$ \\
\hline
\end{tabular}

posés, le fussent-ils au sein de milieux synthétiques ou complexes, gélosés ou liquides.

Sur les milieux solides plus franchement que dans les milieux liquides, elle a montré qu'elle utilise le carbone des seuls hexoses ainsı que celui de certaıns acides organiques.

Dans la mesure ou sa faible crossance peut autoriser des conclusions, cette souche s'est révélée exigeante, et dans les conditions de l'expérimentation, non protéolytıque et d'un équipement enzymatique sommaire. II lu faut, sans aucun doute, des facteurs de croissance qu'elle trouve dans l'œuf, l'extralt de levure ou le sérum; et il est fort probable que la thiamine en soit.
Du point de vue de son métabolisme général 11 convient de retenir la présence d'une catalase puissante, particulıèrement élaborée, signant une haute adaptation à une respiration active en présence d'oxygène. L'existence d'une nitrate réductase témoigneralt en outre qu'elle dispose d'un autre système enzymatique où les nitrates sercient les accepteurs finaux d'hydrogène dans les phosphorylations oxydatives.

Enfin elle ne produit pas d'acide nicotinique, ne tronsforme pas le citrate de fer ammoniacal, ne fixe pas le rouge neutre.

La sensibilité aux antibiotiques assez explicitée dans le tableau IV appelle cependant trois remarques. 
10 La sensibilité à la kanamycine ne s'est manifestée qu'au bout de 15 jours. Même en présence de $32 \gamma / \mathrm{cm}^{2}$, le germe a en effet manifesté une faible velléité de croissance pendant 15 jours. A partir de ce moment les rares colonies qui s'étaient développées en présence de $8,16$. $32 \gamma / \mathrm{cm}^{2}$ se sont résorbées. En présence de $4 \gamma$ une seule colonie s'est développée sans entrave. Dans l'inoculum a dô se trouver un mutant capable de surmonter l'effet bactériostatıque de la kanamycine à cette concentration.

$2^{\circ}$ La très faible culture enregistrée en présence de cyclosérine à la concentration de 10 et $20 \mathrm{\gamma} / \mathrm{cm}^{2}$ ne s'est manifestée qu'après 20 jours d'incubation. La taille et le nombre des colonies sont restés stables par la suite. Après 6 semaines cependant on a pu enregistrer la sortie et la croissance rapide d'une seule colonie en présence de $30 \mathrm{\gamma} / \mathrm{cm}^{2}$. Ici encore un mutant a surmonté l'effet bactériostatique et bactéricide de la cyclosérine.

$3^{\circ}$ A l'égard de l'I. N. H. le germe s'est montré franchement indifférent. Même en présence de $0,5 \gamma / \mathrm{cm}^{2}$ la culture s'est montrée sı luxuriante qu'on pourrait se demander si on n'est pas en présence d'un phénomène d'antibiodépendance, d̀ moins que l'importance de l'inoculum de ce tube explique la richesse exceptionnelle de la culture.

Cette Actinomycétale pourrał être facilement tenue pour une Nocardia à cause de sa morphologie, et plus spécialement pour $N$. forcinca en raison de son origine et de son actıon pathagène.

Mals d'autres critères devraient consacrer ce diagnostic.

Dans la description sommaire qu'on garde de N. farcinica (NOCARD 1888) GORDON et MIHM (1957) croient pouvolr reconnaître $N$. asteroıdes ainsi que deux autres souches voisines de celle-ci les 3318 et 3399 A. T. C. C. que d'autres donnent pour $N$. forcinica.

L'Actinomycétale du Tchad serait-elle assimilable à N. forcinica de NOCARD, sı elle pouvaıt l'être à $N$. asterordes et aux souches A. T. C. C. ?

Si on compare les comportements biochimiques de notre souche, de N. asteroïdes, des souches A. T.C.C., on est frappé par certains caractères communs : absence chez toutes de pouvorr protéolytıque, faible pouvoir fermentatif sur les hydrates de carbone, le glucose excepté ; équi- pement enzymatique semblable en nitrate réductase.

Par contre, on enregistre leur utilısation différente des acides organiques : la souche du Tchad utılise le benzoote et le citrate, mais pas le pyruvate et très peu l'acétote. Les autres, à l'inverse, n'attaquent ni le citrate ni le benzoate, mais le pyruvate et l'acétate.

L'Actınomycétale du Tchad enfin ne dispose pas d'uréase, cet enzyme constitutif de Nocardia.

La seule étude biochımıque laisse done le problème entier et fait ressortir les différences profondes entre l'Actınomycétale du Tchad et les souches types de $N$. farcinica.

Mais on connaît la valeur toute relative des réactions biochimiques d'un germe dans sa défnition, singulıèrement au seın des Nocardiae et pour $N$. asteroldes en particulier. GORDON et MIHM eux-mêmes rapportent les avatars de la souche N.C.T.C. 6531 donnée pour N. gardnier à l'origine, N. asteroïdes par la suite, redevenant N. gardnieri, peu après, pour se trouver, en dernière analyse, classée parmi les streptomycètes à cause de sa constitution lipidique.

Le typage sérologique et l'établissement de la formule antigénique n'emparteraient pas la décision. Laın de là. C'est l'avis du Professeur Gina CASTELNUOVO* qui se déclare incapable de dıagnostiquer nos souches par les méthodes sérologiques tant est confuse la famille des Nocardiae.

Certes cetfe étude sérologique des Nocardice, en faisant ressortir l'intrication extrême des antigènes chez différentes espèces ef la grande diversité, dans une espèce, des types d'équipement antigénique, n'est pas faite pour fixer les idées. Elle a cependant l'avantage de remettre en question l'appartenance authentıque de telle Nacardia au genre Nocardia, de tel Mycobocterium au genre Mycobacterium. C'est elle en effet qui inspira l'étude des lıpides de Mycobacterium rhodocrous et de Mycobacterium pellegrino, aux termes de laquelle ces germes furent à ranger parmı les Nocardiae.

\section{III. - CONCLUSIONS}

Si la morphologie de cette espèce microbienne permet de la classer parmi les Actinomycétales

* Correspondance personnelle. 
(Buchanan) selon PREVOT (1967), son pouvoir pathogène inclinerait à en farre Nocardia farcinica, ordre des Actınobactériales, famille des Actinomycetaceae. Mais, on l'a vu, les observations recueillies au cours de ce travail s'inscrivent en faux contre ce dernier diagnostic.

Sa biochimie est très différente de celles des souches types de $N$. forcinica-asteroïdes et sa difficile adaptation aux milieux liquides, ses longs délais d'incubation l'en éloignent encore. Enfin contrairement aux Nocardiae elle n'a pas cette enzyme constitutive qu'est l'uréase.

Pour parfare le doute sur sa vraie nature, ses victımes développent une allergle des plus franches à l'égard de la tuberculine, elle entoure ses colonies d'une auréole moirée de nature lipıdique et cette même substance grasse qui l'en- robe rend, on l'a vu, sa manipulation difficile. On rapproche aisément ces détalls de sa franche acıdo-résistance et à ce propos on reprend volontiers les définıtions que donne PREVOT (1967) :

- D'une part, des Actınobactériales : « Actinomycétales non acıdo résistantes. »

- D'autre part, des Mycobactériales : « Actinomycétales acido résistantes.» «Acido résistance par enveloppe cireuse».

Il serait donc possible que cette Actinomycétale se définisse mieux comme une Mycobactérıle que comme une Actınobactériale.

D'alleurs l'analyse de ses constituants lipidiques, qui fait l'objet de l'article suivant, confirme nettement l'hypothèse en révélant cette nature de Mycobactérie vraie.

\title{
SUMMARY
}

\begin{abstract}
About the etiology of streptothricosis of the Chad zebu caltle: Nocardiosis or mycobacteriosis ? I. Bacteriological and biochemical study

In zebu cattle of Chad, an actinomycete considered up to the present as belonging to the Nocardia genus, is isolated from suppurated lymphnodes; by a bacteriological study, it is shown that this germ is different from $N$ farcinica and suggested that a chemical analysis of its components could complete the determination.
\end{abstract}

\section{RESUMEN}

En cuanto a la etiologia de la estreptotricosis de los cebues de Chad : $i$ nocardiosis o micobacteriosis ?. I. Estudio bacteriologico y bioquimico

Se aisló, a partir de abscesos ganglionares en cebues de Chad, un germen de la clase de los actınomicetos que se considera pertenecer al genero Nocardia ; Su estudio bacteriologıco muestra que es diferente de N. farcinico e impele, para acabar su determinación, a analizar su constitución químıca.

\section{BIBLIOGRAPHIE}

AWAD (F. I.). - The interrelationship between tuberculosis and bovine Farcy. J. comp. path., $1958,68,3,324-330$.

BONCIU (C.), BONCIU (O.), PETROVICI (M.). - Nocardiose des cobayes et des lapins. Arch. Roum. poth. exp. Microbiol., 1963, 24, 2, 365-378.

CASTELNUOVO (G.), BELLEZZA (G.), DUNCAN (M. E.), ASSELINEAU (J.), - Etude sur les Mycobactéries et les Nocardiae. I.
Constitution antigénique. II. Relations sérologiques entre Mycobactéries et Nocardiae. III. Sensibilité aux phages. Ann. Inst. Past., 1964, 107, 828-844.

GONZALEZ-MENDOZA (A.) et MARIAT (F.).Sur l'hydrolyse de la gélatine comme caractère différentiel entre Nocardia asteroïdes et N. brosiliensis. Ann. Inst. Past., 1964, 107, 4, 560-64.

GORDON (R. E.) and MIHM (J. M.). - A 
comparative study of some strains received as Nocardiae. Journ. Off. Bact., 1957, 73, 1, 15-27.

GORDON (R. E.) and MIHM (J. M.). - A comparison of Nocardia asferoïdes and Nocardia brasiliensis. J. gen. Microbiol., 1959, 20, 1, 129, 135.

GORDON (R. E.) and MIHM (J. M.). - The type species of Genus Nocardia. J. Gen. Microbiol., 1962, 27,1-10.

KURUP (P. V.) and SANDHU (R. S.). - Isolation of Nocardia caviae from soil and its pathogenicity for laboratory animal. Journ. Off. Bact., 1965, 90, 3, 822-823.

LACHAUX ( $P$.). - - Le farcin du bouf. Thèse vétérınaire. Lyon, 1951.

MARIAT (F.). - Activité uréasique des Actinomycètes aérobies pathogènes. Ann. Inst. Past., 1963, 105, 795-797.

MARIAT (F.). - Etude comparative de souches isolées de Nocardia isolées de Mycétomes. Ann. Inst. Past., 1965, 109, 1, 90-104.

MOSTAFA (I. E.). - Study of boylne Farcy in the Sudan. I. Mycology of the disease. J. Comp. Path., 1967, 77, 231-237.

MOSTAFA (t. E.). - Bovine Nocardiosis (cattle farcy) a rewiew. The Veterinary bulletin, 1966, $36,4,189-193$.
NOCARD (E.). - Note sur la maladie des bœufs, connue à la Guadeloupe sous le nom de farcin. Ann. Inst. Past., 1888, 2, 292-302. PERPEZAT (A.), MARIAT (F.), DESTOMBES (P.) ef THOME (M.). - Importance du farcin chez le zébu du Tchad. Bull. Soc. Path. exotique, 1963, 56, 3, 375-383.

PREVOT (A. R.). - Classification des bactéries. In Dumas. Bactériologie Médicale. Edition Flammarion. Mise à jour 1967.

SEGRETAIN (G.), DROUET (G.), MARIAT (F.). - Diagnostic de laboratoire en mycologie médicale, 1964. 2e édition. Editions de la tourelle.

WAKSMAN (S. A.). - The Actinomycètes. Their nature, occurence, activities and importance. 1950. Waltham. Mass U. S. A. Published by the Chronica Botanica Company.

Les travaux qui ont inspiré cet article étaient terminés lorsque nous avons eu connaissance de celui de :

PERPEZAT (A.), DESTOMBES (P.) et MARIAT (F.). - Etude histo-pathologique de la Nocardiose du Bœuf du Tchad et caractères biochimiques de Nocardia farcinica. Paru dans la Revue d'Elevage et de Médecine Vétérinaire des Pays Tropicaux, 1967, 20, 3, 429-435. 